\title{
Evaluation of Incentives for Body Area Network- based HealthCare Systems
}

\author{
Siavash Aflaki, Nirvana Meratnia, Mitra Baratchi, Paul J.M. Havinga \\ Pervasive Systems Group, University of Twente, the Netherlands \\ (s.aflaki, n.meratnia, m.baratchi, p.j.m.havinga) @utwente.nl
}

\begin{abstract}
With ever-increasing advancements of body area networks and participatory sensing, various healthcare applications have emerged. These applications are used to collect physiological and activity data from people and to evaluate their health situation in an online manner. The ultimate goal here is to ensure health and well-being of participants. Although various researches have been performed on underlying system of these applications from the technical point of view, very few have focused on ways to encourage people to use them and to increase their acceptability. In this paper, we present a taxonomy for motivations and incentives used in body area network based healthcare systems. Furthermore, we identify incentives' features and output expectancies and use them in a model to determine important factors that persuade people to accept and use a health monitoring system. Finally, we evaluate each incentive using Analytical Hierarchy Process (AHP) technique to identify the most effective elements of each incentive having a specific goal in mind.
\end{abstract}

\section{INTRODUCTION}

In the past, gathering personal and environmental data was time-consuming, and difficult $[1,2]$. The concept of enabling people to gather data is underpinned by coming about and advancement of mobile phones and their ever increasing ubiquity. Today over two billion people carry mobile or smart phones worldwide [3]. This significant number of mobile devices with unprecedented data gathering, storing and transmission capabilities has brought about vast number of intelligent applications all over the world. Embedding sensors such as cameras, motion sensors, and GPS into mobile phones and their integration with web services and the Internet availability have emerged as a solution for people to collect data about themselves and their environment [4].

Participatory sensing is a people-centric data collection and data sharing approach, in which data is gathered using personal mobile devices by individuals, groups, or communities $[5,6]$. The advancement of the new technology on the one hand and the rise of some serious environmental concerns in the globe on the other hand have caused the emergence of applications of participatory sensing. For example, monitoring quality of air and noise level, as two important global concerns, through participatory sensing can help societies to improve their quality of life. Another application domain of participatory sensing gaining popularity is healthcare. Monitoring patient's health is a critical issue for health and disease management systems [3]. With the ever increasing advancement in the domain of sensors to measure vital signs and physiological data, low-power microelectronics, and wireless communication, many mobile healthcare systems have been emerged whose focus is on effective ways of collecting health related data and provision of fast medical support. These systems typically rely on existence of a body area network composed of a number of sensor nodes attached to the body, embedded in cloths, or carried by people. Enabling and empowering citizens to fight with diseases by promoting a preventive lifestyle and early diagnosis as well as to help them to stay healthy and to preserve their well-being are the main objectives of participatory sensing based medical systems [7].

Although technology is advancing fast in both body area networks and participatory sensing areas, there is no strong and clear approach to encourage people to actively use health monitoring systems. Our study shows that number of active participants in health monitoring projects remains to be limited.

In this paper, we present a detailed overview and a taxonomy of incentives and motivations used for body area network-based healthcare systems. The presented taxonomy and its detailed analysis are intended to provide a guideline to design appropriate incentive tools in this domain. Such guideline will lead to a better understanding of the relation between participants' needs, goals, intention, and system objectives. To clarify which factors have more effects on people to use an incentive, we also present a trade-off model based on Theory of Reasoned Action (TRA) [8] and Technology Acceptance Model (TAM) [9]. An evaluation of our model using Analytical Hierarchy Process(AHP) [10] will also be presented. To the best of our knowledge, this is the first time that a systematic model-based approach is designed to analyse incentives for body area network and participatory sensing based healthcare systems.

The rest of this paper is organized as follows. In Section II, incentive concepts and parameters are presented, which will be used to define the taxonomy presented in Section III, Our incentive acceptance model is presented in Section IV, while its evaluation and discussions are presented in Section $\mathrm{V}$ and VI, respectively. Section VII draws some conclusions and highlights the future work.

\section{INCENTIVE CONCEPTS AND PARAMETERS}

Before presenting our taxonomy of incentive tools used for body area network-based healthcare systems, we first explain the concepts and parameters of such incentive tools. 
TABLE I: A DETAILED TABLE OF BAN RESEARCHES

\begin{tabular}{|c|c|c|c|c|c|c|c|c|c|c|c|c|}
\hline \multirow[b]{2}{*}{ Research } & \multirow[b]{2}{*}{$\operatorname{Sen} *$} & \multirow[b]{2}{*}{$\mathbf{I}^{*}$} & \multirow[b]{2}{*}{$\mathbf{G}^{*}$} & \multirow[b]{2}{*}{$C^{*}$} & \multicolumn{2}{|c|}{ Motivation /Incentive } & \multirow[b]{2}{*}{ Used Technique } & \multicolumn{3}{|c|}{ Demography } & \multirow[b]{2}{*}{ Dur* } & \multirow[b]{2}{*}{ Year } \\
\hline & & & & & motivation & Incentive & & Age & $\operatorname{sex}$ & Cou* & & \\
\hline CRMS [19] & $\checkmark$ & $\checkmark$ & & & $\begin{array}{l}\text { Health condition's awareness, using } \\
\text { technologies, peace of mind }\end{array}$ & $\begin{array}{c}\text { Well-being Healthcare } \\
\text { services }\end{array}$ & -------- & $21-90$ & Mix & AUS & $2 \mathrm{Y}$ & 09-11 \\
\hline DietSence [20] & $\checkmark$ & $\checkmark$ & & & \multicolumn{2}{|l|}{ Well- being } & Establishing an obligatory course & Teen & Mix & us & $3 \mathrm{w}$ & 11 \\
\hline Jogfalls [21] & $\checkmark$ & $\checkmark$ & & & $\begin{array}{l}\text { Health condition's awareness- } \\
\text { Treatment- Reducing weight }\end{array}$ & Well- being & $\begin{array}{c}\text { Mobile application with personalize } \\
\text { messages }\end{array}$ & $18-60$ & Mix & IND & $63 \mathrm{D}$ & 10 \\
\hline Houston [22] & $\checkmark$ & & $\checkmark$ & & $\begin{array}{c}\text { physical activity -Loosing weight- } \\
\text { Socializing }\end{array}$ & Well-being-Socializing & $\begin{array}{c}\begin{array}{l}\text { Sharing group's data, chat rooms(for } \\
\text { friends) }\end{array} \\
\end{array}$ & $28-42$ & F & CAN & $3 \mathrm{w}$ & 06 \\
\hline Get up move [22] & $\checkmark$ & $\checkmark$ & & & Loosing weight & Game & Exergame & ---- & ---- & ---- & ---- & ---- \\
\hline $\begin{array}{c}\text { Nint endo Packet } \\
\text { Pikachu [22] }\end{array}$ & $\checkmark$ & $\checkmark$ & & & Loosing weight - Physical activities & Game & $\begin{array}{l}\text { Stationary bike that uses a virtual } \\
\text { training course on a screen }\end{array}$ & ---- & ---- & ---- & ---- & ---- \\
\hline Fish'n'Steps [23] & $\checkmark$ & & $\checkmark$ & & $\begin{array}{c}\text { Physical activity- Wining in a } \\
\text { competition }\end{array}$ & $\begin{array}{l}\text { Financial support- } \\
\text { Competition-Game }\end{array}$ & $\begin{array}{c}\text { Making a competition-Fish } \\
\text { growing(Exergame) }\end{array}$ & $23-63$ & Mix & us & $14 \mathrm{w}$ & 06 \\
\hline Tamagotchi [24] & $\checkmark$ & $\checkmark$ & & & physical activities & Game & $\begin{array}{c}\text { T amagotchi- e- money (persuasion } \\
\text { game) }\end{array}$ & Teen & Mix & JPN & $|---|$ & 04 \\
\hline PHM [25] & $\checkmark$ & $\checkmark$ & & & $\begin{array}{c}\text { Health condition's awareness- } \\
\text { Treatment-Using new technologies }\end{array}$ & $\begin{array}{c}\text { Well-being- } \\
\text { Healthcare services }\end{array}$ & $\begin{array}{l}\text { Hospital's facilities, speaking with } \\
\text { nurses and doctors }\end{array}$ & $22-90$ & Mix & AUS & --- & 07 \\
\hline MobiHealth [25] & $\checkmark$ & $\checkmark$ & & & $\begin{array}{l}\text { Health condition's awareness - Using } \\
\text { technologies }\end{array}$ & $\begin{array}{l}\text { Healthcare services- } \\
\text { Well- being }\end{array}$ & $\begin{array}{c}\text { Hospital's facilities, speaking with } \\
\text { nurses and doctors }\end{array}$ & ----- & Mix & NED & ---- & 07 \\
\hline $\begin{array}{l}\text { Fairness and social } \\
\text { welfare }[26]\end{array}$ & $x$ & & $\checkmark$ & & Altruism & $\begin{array}{l}\text { Competition- } \\
\text { Financial support }\end{array}$ & Money & ---- & $\mid---$ & SIN & --- & 12 \\
\hline $\begin{array}{c}\text { Dynamic pricing } \\
{[27]} \\
\end{array}$ & $\checkmark$ & $\checkmark$ & $\checkmark$ & $\checkmark$ & Financial reasons & Financial support & Dynamic pricing incentive & ---- & ---- & us & ---- & 10 \\
\hline Mobile Panflu & $\checkmark$ & & & $\checkmark$ & Altruism & Game & Serious game & ---- & --- & --- & ---- & ---- \\
\hline ErgoActive [28] & $\checkmark$ & $\checkmark$ & & & Well -being & Game & $\begin{array}{l}\text { Exergame (ride a bike in tour de } \\
\text { France with your speed) }\end{array}$ & ----- & Mix & GER & ---- & 10 \\
\hline $\begin{array}{l}\text { EscapeFrom } \\
\text { Diab[29] }\end{array}$ & $x$ & $\checkmark$ & & & Obligation & Game -T reatment & Education game & $10-12$ & Mix & us & --- & 10 \\
\hline Wii [30] & $\checkmark$ & & $\checkmark$ & & $\begin{array}{c}\text { Physical, mental and social well being- } \\
\text { Socializing }\end{array}$ & $\begin{array}{l}\text { Socializing-Game- } \\
\text { Competition }\end{array}$ & Exergame & Elderly & Mix & GER & --- & 09 \\
\hline SunSports Go [28] & $\checkmark$ & $\checkmark$ & $\checkmark$ & & Well - being-Socializing & Socializing- Game & Exergame (biathlon) & ---- & Mix & ---- & --- & ---- \\
\hline Nanoswarm [31] & $x$ & $\checkmark$ & & & Obligation & $\begin{array}{c}\text { Education game and } \\
\text { treatment }\end{array}$ & Serious game & $9-11$ & Mix & us & $|----|$ & 07 \\
\hline Robot Games [32] & $\checkmark$ & & $\checkmark$ & & Socializing- Well -being & Game & A real robot game & ---- & Mix & SPN & ---- & 10 \\
\hline MINWii [33] & $x$ & $\checkmark$ & & & Treatment & Game & Game & Elderly & Mix & FRA & $3 \mathrm{M}$ & 11 \\
\hline $\begin{array}{l}\text { Exergaming for } \\
\text { children [34] }\end{array}$ & $\checkmark$ & $\checkmark$ & & & Obligation-T reatment & Game & $\begin{array}{l}\text { Exergame(USING Xbox } 360 \\
\text { controller) }\end{array}$ & children & Mix & CAN & --- & 12 \\
\hline $\begin{array}{l}\text { A Location-Based } \\
\text { Incentive [35] }\end{array}$ & $\checkmark$ & $\checkmark$ & $\checkmark$ & $\checkmark$ & Financial reasons & Financial support & Location-based reverse auction & ---- & ----- & us & --- & 12 \\
\hline
\end{tabular}

\section{A. Incentives and motivations}

Making people interested in technology and persuading them to use and accept a system is important in people-centric research [11]. Incentives are external factors which are designed to influence behaviour of individual, groups or societies [12]. The role and effectiveness of incentives for motivating people cannot fully be measured unless people's needs, goals and concerns are first understood. To this end, understanding why people participate in such research and accept to use the technology seems crucial and identification of incentives which have convinced people to participate in researches is indispensable. There are cognitive and motivational factors for people's participation and behavioural changes [13]. Some motivational theories have argued that participation maybe caused by sense of personal commitment to be good or it stems from an external obligation [14]. People usually participate in public-centric projects based on motivations such as desire to help scientific research, competition, gaining technical knowledge, and improvement of their skills, being in a team and having social ties, recognition and enhancement of their status and reputation, altruism reasons, having fun, reciprocity, intellectual stimulation, and sense of obligation to contribution [15]. Explaining the value of their participation can increase the level of people's contribution dramatically. From another point of view, people may come in to action because of their interest or because of reward awaiting them, but results in [16] show that higher financial incentives lead to poorer results and rewards make the focus narrower. In [17] target groups were divided into two groups, 'reward' group and 'no-reward' group. The results illustrated that although individuals in 'reward' group showed better compliance at the beginning, worse compliance occurred in the long run in comparison with 'no-reward' group. Ryan [14] has grouped all motivations mentioned before to intrinsic motivation and extrinsic motivations. Intrinsic motivations are those that excite people to do something for the sake of enjoyment of the activity itself. In comparison, extrinsic motivations are those motivations which are used to do something for a specific adaptable outcome such as rewards [14]. The key point here is that stimulation of intrinsic motivations can lead to a valuable 


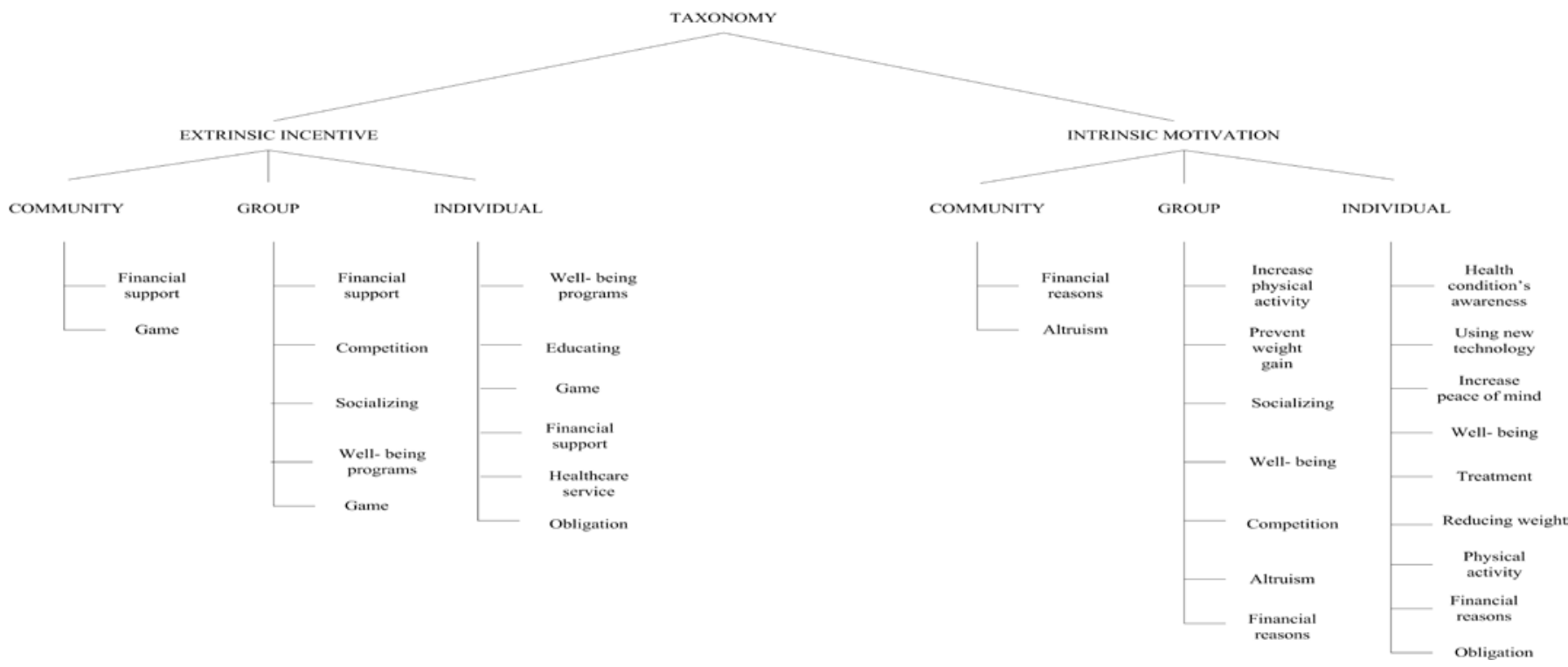

Fig. 1. Taxonomy of incentives and motivations

contribution in comparison with extrinsic motivations. Intrinsic motivations, that are personal motivations, entice people to act enthusiastically based on their needs. Despite the fact that intrinsic motivations are good drives, extrinsic incentives are also effective. We believe that if intrinsic motivations match extrinsic incentives, or in other words if what motivates people from inside matches facilities and supports provided externally, better results can be achieved.

\section{B. Target groups}

Incentives may be designed for three target groups, namely, individuals, groups, and communities.

Individual: Incentive tools addressing this group are designed to motivate individuals and consequently focus on personal motivations and gains.

Group: Incentive tools addressing this target group focus on a group of people, which do not necessarily share the same goals or concerns. However, they do share some characteristics such as age and education.

Community: Compared with incentive tools designed for groups, incentive tools addressing this group not only have a wider focus in terms of number of participants but also participants share common goals, interests, or concerns.

\section{TAXONOMY}

The taxonomy presented in this paper is produced by analysing 23 research papers and projects in body area network-based healthcare domain. This taxonomy gives an overview of intrinsic motivations and extrinsic incentives that have encouraged people to participate in these projects. We analyse intrinsic motivations and extrinsic incentives for three types of target groups, i.e., individuals, groups, and communities.

As it can be seen in Table I, participants' age ranges from young (children) to old (elderly). Most of the body area network-based researches address individual target groups. Gaming seems to be a popular incentive for this target group, although it is also used for groups and communities. Socializing and competition are used as incentive for projects addressing groups and communities. There are also a number of projects, in which participation of children and teenagers were compulsory but games were used to improve their performance. The term "used technique" in Table I describes the method used for developing an incentive.

We use Table I to define our taxonomy of incentives and motivations for all three target groups (community, group, and individual). In terms of intrinsic motivation, most individual motivations are related to well-being and treatment such as reducing weight, awareness of health condition and carrying out physical activities. Being with friends, finding new friends, being in touch with other people who have the same health problems, and sense of competition are considered as powerful intrinsic motivations especially for groups (socializing). Altruism and financial reasons stand out as intrinsic motivations for communities.

Similar to intrinsic motivations, the most common extrinsic incentive for all three target groups are related to well-being and treatment. Well-being programs, gaming and having fun, financial support, receiving healthcare services, and obligation have been considered as extrinsic incentive for individuals, while financial support, competition, socializing, gaming have been considered for groups. Communities have often used financial support and gaming to help people to remain healthier and active by using healthcare systems.

We categorize intrinsic motivations to financial reasons, well-being, socializing, sense of competition and treatment and provide the following definitions:

- Financial reasons: Receiving financial benefit is a motivation for people.

- Well-being: Being healthy, reducing weight, awareness of health are motivations of people.

- Sense of competition: Being in competition with other people. 
- Treatment: Receiving a treatment for a disease which the participant suffers from.

We group extrinsic incentive into financial support, wellbeing programs, gaming, socializing and receiving healthcare services which are defined as

- Financial support: Monetary rewards received in case of using a healthcare system.

- Well-being programs: Programs to Improve or preserve health condition

- Gaming: Playing a virtual or physical game and having fun.

- Socializing: Chatting with friends, social networking, group gatherings plus out door physical activities.

- Healthcare services: Healthcare related service received for free or reduced price.

\section{INCENTIVES' ACCEPTANCE MODEL}

To better understand the effectiveness of incentives for different objectives and goals, we develop an incentive acceptance model. The first step in designing the model is to identify the elements which have a substantial impact on people's intention. We use two well-known theories for designing this model. The first theory is Technology Acceptance Model (TAM) [9], which defines how users accept and use a technology. The second one is the Theory of Reasoned Action (TRA) [8], which predicts behavioural intention. TAM states that perceived ease of use and perceived usefulness have strong influence on people's intention. Unified Theory of Acceptance and Use of Technology (UTAUT) [18] explain that effort expectancy, social influence and performance expectancy affect people's intention [18]. TRA theory clarifies that behavioural intention has two main components, i.e., (i) attitude towards taking actions, and (ii) subjective norms. This means that to participate in a voluntary action, one asks himself a number of questions such as: What will happen after doing this action? What is the outcome of the action? Is the outcome desirable? What will be others' expectations? How much effort do I need to put into this action?

As illustrated in Fig.2., our model has two main blocks Incentives' Features and Output Expectancy, which have direct effects on people's intention. Incentives' features block is comprised of four sub-functions:

- Perceived usefulness, which is defined as the degree to which a person believes that the incentive will enhance his/her health condition.

- Efficiency, which is defined as how efficiently goals are reached using a specific incentive.

- Effort, which is defined as energy, time or money spent to use the incentive tool. Effort is also related to perceived ease of use and complexity of the use of incentive tool.

- Support, which is defined as the degree to which a person needs any kind of help to use the incentive.

Output expectancy is divided into:
- Performance improvement, which is defined as consequences of using the incentives on person's health condition. It is mentioned in [18] that the performance improvement is the strongest sub-factor of intention.

- Social influence, which is defined as the degree to which people's emotion, opinion or behaviour changes by using the incentive tool.

- Economic impacts, which is defined by financial gains in using the incentives.

We believe that features and output expectancy have a direct impact on people's intention in using healthcare systems. External factors such as time and participant's availability on the other hand may be an obstacle in bringing intentions to actions.

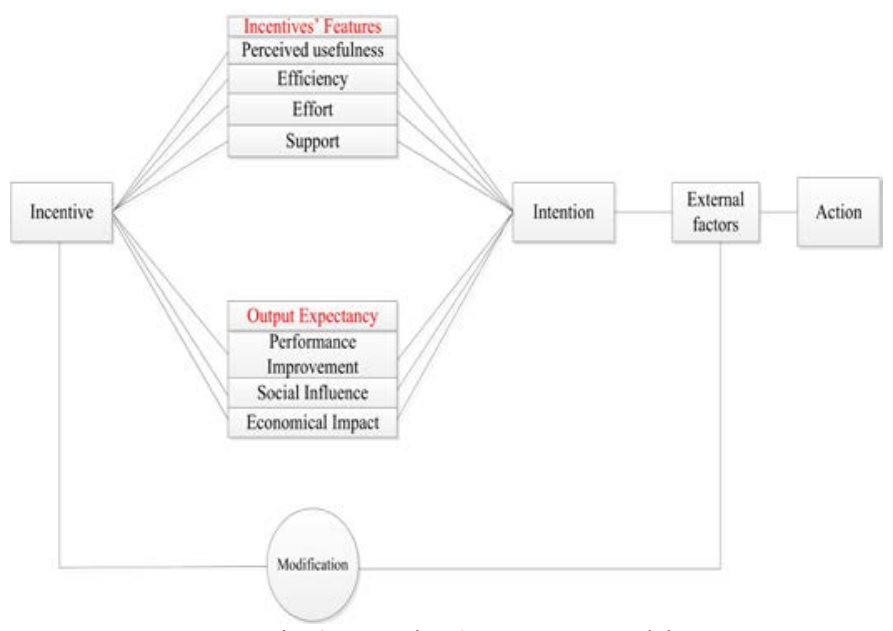

Fig. 2. Incentives' acceptance model

\section{EVALUATION OF INCENTIVE TOOLS}

Understanding weight of each sub-function on people's intention and the weight of each sub-function in each incentive help in the design of effective incentive tools. By doing so, firstly, the best and the worst effective incentives can be identified. Secondly, strengths and weakness of each incentive can be understood. To reach these goals, we use the Analytical Hierarchy Method (AHP), one of the best known techniques in choosing the most contributing factor among several alternatives. Producing weights by comparing subfunctions and incentives with the help of people themselves is the advantage offered by our technique. We design a questionnaire to identify (i) importance degree of each subfunction relative to other sub-functions, and (ii) importance degree of each incentives relative to other incentives.

We asked 20 individuals to fill in our questionnaire and analyse their answers to find out the weights of our model. Most of participants are Ph.D. students between 21 to 30 years of age. The result illustrated in Fig.3. shows that the perceived usefulness and efficiency are perceived to be more important than effort and support by participants. This means that participants have high expectation from an incentive tool offered to them in terms of usefulness and efficiency. Effort 
has the minimum weight in the features' sub-factors. This shows its low level of importance.

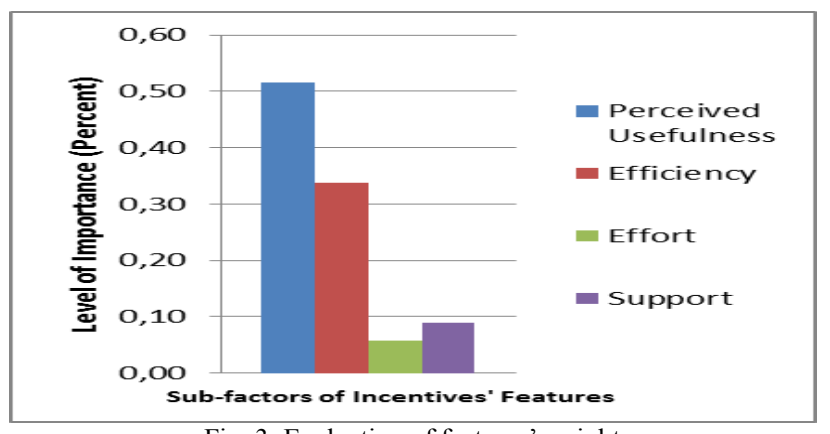

Fig. 3. Evaluation of features' weight

Fig. 4. shows comparison between the five incentives previously mentioned base on features' sub-factors. It can be seen that participants consider receiving healthcare services and gaming to be the most useful and efficient incentive tools. Moreover, participants expect to need to put more effort in using these two incentive tools.

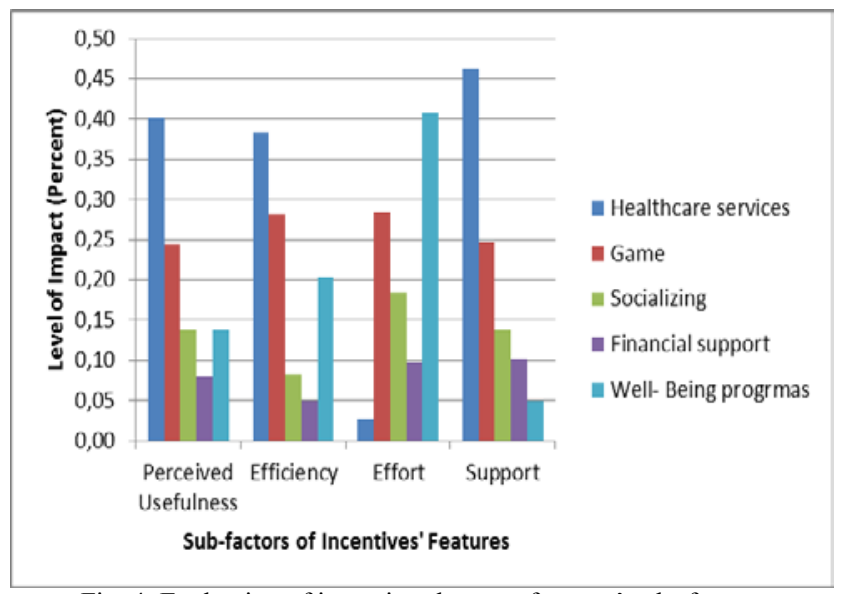

Fig. 4. Evaluation of incentives base on features' sub- factors

Fig. 5. depicts that participants find performance improvement to be the most important in output expectancy sub-factor. This means that participants are more attracted to incentive tools that offer them health improvement and do not care much about social influence and economical benefits of them.

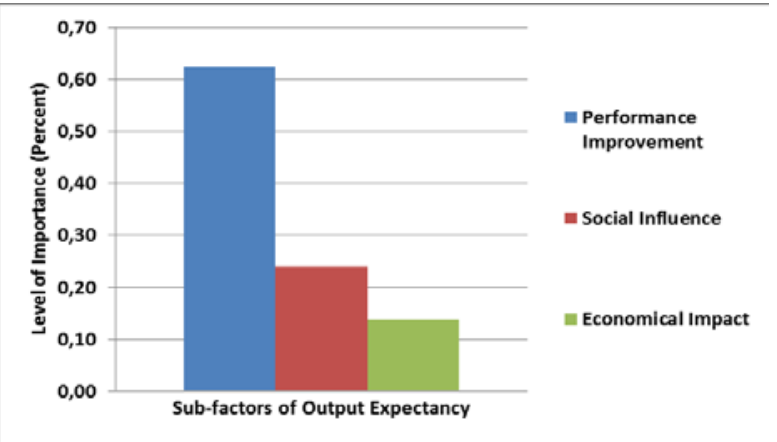

Fig. 5. Evaluation of output expectancy
Results of comparing incentives base on output expectancy sub-factors are shown in Fig. 6. Although healthcare services are identified as the most important factor in performance improvement, gaming is considered to be the most powerful incentive in changing people's behaviour (social influence). As expected, receiving free or reduced price healthcare services are considered to be more effective than getting money directly.

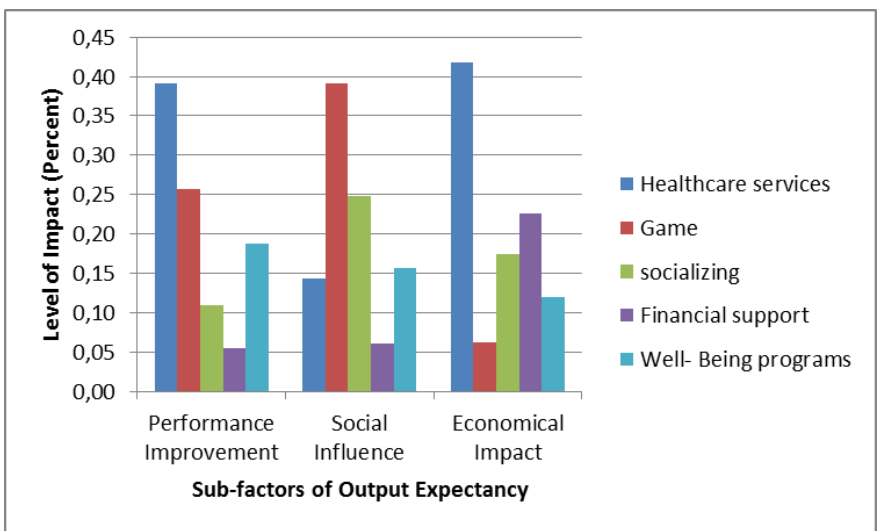

Fig. 6. Evaluation of incentives base on output expectancy sub- factors

Finally, in Fig. 7. we illustrate which incentive has the highest potential to be accepted by participants. The results show that receiving healthcare services is the most acceptable incentive, followed by gaming, well-being programs, and socializing. Receiving financial supports is the least valued incentive.

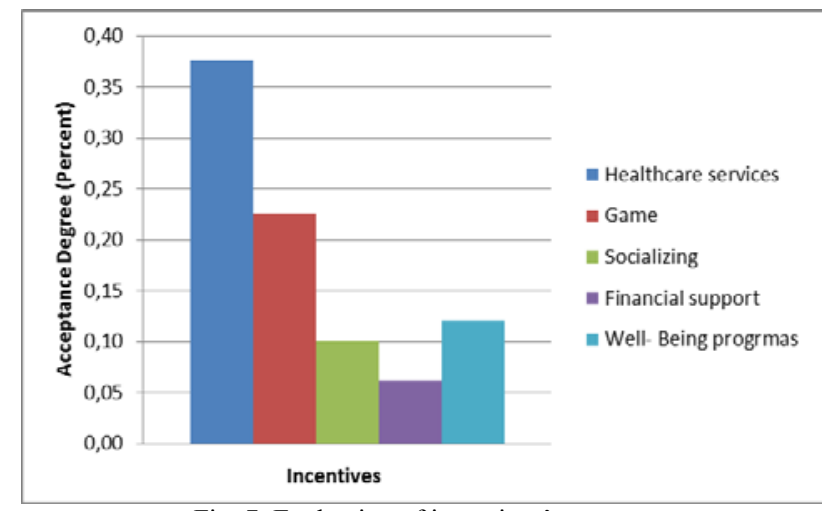

Fig. 7. Evaluation of incentives' acceptance

\section{CONCLUSION}

In this paper, we present a taxonomy of incentives and motivations used so far for body area network and participatory based healthcare systems. To evaluate the acceptability of the identified incentives we design a model, to find out the importance of different factors in changing people's intention and in encouraging them to use and accept a health monitoring system. The output factors of this model can be used to select a proper incentive. Few interesting points are identified based on a questionnaires filled by 20 individuals. Firstly, the most acceptable incentive is considered to be receiving healthcare services, while the most 
selected incentive by previous researches has been gaming. Secondly, the questioned group generally think more about treatment than prevention. This can be clearly justified by the fact that well-being programs are ranked lower than receiving medical services and gaming. Thirdly, efficiency and usefulness are considered to be the most important features of incentive tools. Finally, receiving free or reduced price healthcare services are considered more effective than getting money directly. Regarding these results we can infer that a thorough pre-analysis of incentive tools using a proper methodology can result in proper selection of them for encouraging participants.

\section{ACKNOWLEDGMENT}

This work is partially supported by the SWELL project.

\section{REFERENCES}

[1] E. Paulos, R. J. Honicky, and E. Goodman, "Sensing atmosphere," In Proc. ACM Conference on Embedded Networked Sensor Systems, Sydney, Australia, 2007.

[2] N. Eagle and A. Pentland, "Reality mining: sensing complex social systems," Personal Ubiquitous Computing., vol. 10, pp. 255-268, 2006.

[3] J. Burke, A. Jeffrey, D. Estrin, et al. Participatory sensing. UC Los Angeles: Center for Embedded Network Sensing. Tech. Rep., 2006.

[4] J. Goldman, K. Shilton, et al. "Participatory sensing: A citizenpowered approach to illuminating the patterns that shape our world." Woodrow Wilson International Center for Scholars, Washington, D.C., Tech. Rep., 2009.

[5] D. Estrin. (2010, "Participatory Sensing: citizen science, scientific citizens, computational thinking," [online], Available at: "http://research.cens.ucla.edu/people/estrin/resources/talks/2010-feb01-participatory-sensing.pdf

[6] N. D. Lane, E. Miluzzo, L. Hong, D. Peebles, T. Choudhury, and A. T Campbell, "A survey of mobile phone sensing," Communications Magazine, IEEE, vol. 48, pp. 140-150, 2010.

[7] E. Monton, J. F. Hernandez, et al., "Body area network for wireless patient monitoring," Communications, IET, vol. 2, pp. 215-222, 2008.

[8] B. H. Sheppard, H. Jon, and P. R. Warshaw, "The theory of reasoned action: A meta-analysis of past research with recommendations for modifications and future research," Journal of Consumer Research, vol. 15, pp. 325-343, 1988.

[9] F. D. Davis, "User acceptance of information technology: system characteristics, user perceptions and behavioral impacts," Int. J. ManMachine Studies, vol. 38, 1993.

[10] T. Saaty, "Axiomatic foundation of the analytic hierarchy process," Management Science, vol. 32, 1986.

[11] L. Juong-Sik and H. Baik, "Sell your experiences: a market mechanism based incentive for participatory sensing," in Proc. International Conference Pervasive Computing and Communications, pp. 60-68, 2010.

[12] D. Balassanian, "Incentive systems: incentives, motivations and development performance," [online], Available: http://www.undp.org/content/undp/en/home/librarypage/capacitybuilding/incentive-systems-incentives-motivation-and-developmentperformance-/, 2006.

[13] F. Olivera, P. S. Goodman, and S. S.-L. Tan, "Contribution behaviors in distributed environments," MIS Quarterly, vol. 32, pp. 10-20, 2008.

[14] R. Ryan and E. Deci, "Self-determination theory and the facilitation of intrinsic motivation, social development, and well-being," American Psychologist, vol. 55, pp.110-1125, 2000.

[15] O. Nov, D. Anderson, and O. Arazy, "Volunteer computing: a model of the factors determining contribution to community-based scientific research," In proc. 19th international conference on World wide web, Raleigh, North Carolina, USA, 2010.

[16] S. Glucksberg and R. W. Weisberg, "Verbal behavior and problem solving: Some effects of labeling in a functional fixedness problem," Journal of Experimental Psychology, vol. 71, pp. 18-24, 1966.
[17] A. Kohn, "Punished by rewards: the trouble with gold stars, incentive plans, A's, praise, and other bribes," The Journal of Extension, vol. 32, 1993.

[18] V. Venkatesh, M. G. Morris, B. D. Gordon, and F. D. Davis, "User acceptance of information technology: toward a unified view," MIS Quarterly, vol. 27, pp. 425-478, 2003.

[19] P. Leijdekkers, V. Gay, and E. Barin, "Trial results of a novel cardiac rhythm management system using smart phones and wireless ECG sensors," In Proc. International Conference on Smart Homes and Health Telematics: Ambient Assistive Health and Wellness Management in the Heart of the City, Tours, France, 2009.

[20] S. Reddy, A. Parker, et al., "Image browsing, processing, and clustering for participatory sensing: lessons from a DietSense prototype," In Proc. 4 workshop on Embedded networked sensors, Cork, Ireland, 2007.

[21] L. Nachman, A. Baxi, et al. "Jog falls: a pervasive healthcare platform for diabetes management," In Proc. 8th international conference on Pervasive Computing, Helsinki, Finland, 2010.

[22] S. Consolvo, K. Everitt, et al., "Design requirements for technologies that encourage physical activity," in Proc. Conference on Human Factors in Computing Systems, Canada, 2006.

[23] J. Lin, L. Mamykina, et al., "Fish'n'steps: encouraging physical activity with an interactive computer game," Ubiquitous Computing, $\mathrm{p}$ 261, 2006.

[24] J. Hyeon "Pervasive healthcare: an incentivized way of encouraging physical activity in a social network," [online] , Available at:http://wwwpersonal.umich.edu/ thejoo/files/Hyeon_Joo_SI642_fina 1 paper.pdf, 2010.

[25] V. Jones, V. Gay, and P. Leijdekkers, "Body sensor networks for mobile health monitoring: experience in europe and australia, " in Proc. Fourth International Conference on digital society , pp. 204-209, 2010.

[26] L. Tie and T. Chen-Khong, "Fairness and social welfare in incentivizing participatory sensing," in Proc. Sensor, Mesh and Ad Hoc Communications and Networks, 2012, pp. 425-433.

[27] J.-S. Lee and B. Hoh, "Dynamic pricing incentive for participatory sensing," Pervasive and Mobile Computing, vol. 6, pp. 693-708, 2010.

[28] S. Gobel, S. Hardy, et al. "Serious games for health: personalized exergames," In Proc. the international conference on Multimedia, Firenze, Italy, 2010.

[29] H. Kharrazi, A. Faiola, and J. Defazio, "Healthcare game design: behavioral modeling of serious gaming design for children with chronic diseases," in Human-Computer Interaction. Interacting in Various Application Domains. vol. 5613, pp. 335-344, 2009.

[30] N. Cornelius, "Wii play with elderly people ," International reports on social informatics workshop, Germany, 2009.

[31] D. Thompson, T. Baranowski, et al. "In Pursuit of Change: Youth Response to Intensive Goal Setting Embedded in a Serious Video Game," J Diabetes Sci Technol, vol. 1, pp. 907-918, 2007.

[32] S. Hansen and S. Ontañón, "A software framework for multi player robot games," in Social Robotics. vol. 6414, pp. 131-140, 2010.

[33] M. Boulay, S. Benveniste, et al., "A pilot usability study of MINWii, a music therapy game for demented patients," Technology and Health Care, vol. 19, pp. 233-246, 2011.

[34] H. A. Hernandez, T. C. N. Graham, et al., "Design of an exergaming station for children with cerebral palsy," In Proc. Conference on Human Factors in Computing Systems, Austin, Texas, USA, 2012.

[35] L. Juong-Sik and H. Baik, "Sell your experiences: a market mechanism based incentive for participatory sensing," in Proc. Pervasive Computing and Communications (PerCom), pp. 60-68, 2010. 